\title{
Students' Satisfaction with E-learning during COVID-19 at a Private Medical College.
}

1. BDS, M.Phil (Dental Materials) Demonstrator Medical Education Shalamar Medical and Dental College.

2. MBBS

Demonstrator Medical Education Shalamar Medical and Dental College.

3. MBBS, DLO (Diploma in Laryngo Otorhinology)

Director Medical Education Shalamar Medical and Dental College.

4. BDS

Post Graduate Trainee Oral and Maxillofacial Surgery KEMU/Mayo Hospital.

Correspondence Address:

Dr. Sundus Iftikhar

Department of Medical Education.

13, E-2 Wapda Town Lahore.

sundus@iftikhar.me

Article received on:

14/09/2020

Accepted for publication:

$02 / 11 / 2020$

\begin{abstract}
Sundus Iftikhar ${ }^{1}$, Iqra Aziz ${ }^{2}$, Syed Hasan Shoaib ${ }^{3}$, Ahmad Shafique ${ }^{4}$
\end{abstract}
ABSTRACT... Objective: To evaluate students' satisfaction of E-learning at a private teaching medical college during COVID-19 lockdown. Study Design: Cross Sectional Descriptive study. Setting: Shalamar Medical and Dental College. Period: April 2020 to July 2020. Material \& Methods: A standardized and validated questionnaire (SEEQ) was disseminated among MBBS students of SMDC. The questionnaire contained open ended and closed ended questions; the latter were based on likert scale. Results: A total of 365 students responded to the questionnaire with $57 \%$ and $43 \%$ of the respondents being females and males respectively. Overall, the 3rd, 4th and 5th year MBBS students seemed more satisfied with online lectures (52-54\%) compared with $1^{\text {st }}$ and $2^{\text {nd }}$ year MBBS students (26\%). The students showed dissatisfaction on assignments and assessments being taken on Moodle. The connectivity problem was seen as a major concern for the students. However the students appreciated that the sessions were recorded regularly and available on YouTube channels. Conclusion: The findings of our study showed that $1^{\text {st }}$ and $2^{\text {nd }}$ year students were not mentally prepared for the sudden paradigm shift from traditional to online teaching. However the students realized that gradual shift was not possible in the current scenario and were generally satisfied with E-learning. It is advisable to adopt a blended approach initially before converting the entire learning experience on online media

Key words: Asynchronous, E-Learning, Moodle, Online Learning, Satisfaction, Synchronous, Webinar.

Article Citation: Iftikhar S, Aziz I, Shoaib SH, Shafique A. Students' Satisfaction with E-learning during COVID-19 at a Private Medical College. Professional Med J 2021; 28(6):914-920. https://doi.org/10.29309/TPMJ/2021.28.06.6151

\section{INTRODUCTION}

Worldwide, online classes are conducted in two ways: synchronous (real-time) or asynchronous (delayed time). All the professions, including healthcare, have adopted both these ways to deliver information to students. ${ }^{1}$ For synchronous lectures, a webinar is considered an effective tool as it is easy to use and inexpensive. The faculty and students use their home computers and the internet to access the webinar. Apart from this, there are no additional costs to use it. ${ }^{2}$ Compared with real-time sessions, asynchronous sessions have the advantage that they have the flexibility of time. Additional links to research papers or websites can be provided to facilitate learning in both synchronous and asynchronous teaching. ${ }^{3}$

Many studies in the past have aimed to compare traditional face-to-face lectures with online lectures. Ross et al. concluded that while there was no significant difference between the two instructional media for simple lower level of cognitive learning but for complex higher levels of cognitive learning like analyzing or creating, the face-to-face learners performed significantly better. $^{4}$

Due to the Covid-19 pandemic, the government of Pakistan imposed a country-wide lockdown closing all educational institutes for an undefined period. The lockdown resulted in a significant educational loss of the students of various disciplines, including Medicine. In an attempt to find a solution to this problem, the Department of Medical Education and IT at Shalamar Medical and Dental College (SMDC) arranged live lecture sessions on a webinar and some recorded lectures to be uploaded on Moodle and 
YouTube channels. Literature review suggests that recorded lectures should accompany face-to-face interactions for improved learning. Therefore, a "blended learning approach" should be adopted and lectures should be customized according to the needs of the learners. ${ }^{5} \mathrm{It}$ is for this reason that both synchronous and asynchronous sessions were arranged. Webinar has been used extensively in medical education worldwide, mainly for continued medical education or as part of blended learning approach. ${ }^{6,7,8}$ Similarly, YouTube accounts have been created by many medical schools to assist the students in learning the subject. YouTube channel accounts by medical schools provide credible information and assist the students to learn from a massive online library. ${ }^{9}$ Similarly, Moodle (Modular Object Oriented Dynamic Learning Environment) has been selected by many educational institutes because it is easy to use and provides flexibility and interactive environment. Faculty can also create assignments and examinations in the course. ${ }^{10}$ Therefore, these tools were used to deliver lectures for students.

Several advantages of E-learning have been identified, for example, there is no restriction on timings for asynchronous sessions. It encourages adult learning principles as the student is selfmotivated to learn via digital means and does not rely on teacher's presence. Additionally, uniformity with regards to taught material and other resources is maintained for each student. However the access to internet connection and availability of gadgets is a challenge. ${ }^{11}$

This study aims to address the scarcity of scientific studies in South Asian region regarding the utility of online teaching at present in the current scenario. The rationale of the study was to determine the success of online teaching at a private teaching medical and dental college in Lahore, Pakistan during lockdown by evaluating the students' satisfaction and acceptance of the online classes. Since the college did not provide the required infrastructure to the students so this study will aim to find out the feasibility of online teaching. The findings will help the college to decide whether online means of education can be adopted as part of blended learning approach in future.

\section{MATERIAL \& METHODS}

This study is a cross sectional study aimed at analyzing students' satisfaction of E-learning carried out at Shalamar Medical and Dental College. Shalamar Medical College is situated in Lahore and is one of the leading private medical colleges of the country. After the lockdown was imposed, the schedule of lecture sessions was prepared and disseminated among faculty and students. A daily log of students' attendance in webinar sessions and Moodle entries was maintained. Synchronous teaching took place on webinar where the links for pre-scheduled live sessions were shared with students of the respective classes and live online lectures were conducted. The faculty was given the option of taking lectures from home or from college. It was assumed that all the students had access to internet facilities at home. In order to facilitate the students who had connectivity issue during a particular the live lectures were also recorded and uploaded on YouTube accounts of respective classes. The recorded YouTube lectures became a part of the asynchronous teaching. Apart from this the asynchronous teaching also took place on Moodle where pre-recorded lectures were uploaded by teachers. The topics that the teachers perceived to be comparatively less important and did not require any discussion were pre-recorded and uploaded on Moodle.

After obtaining permission from the IRB (Institutional Review Board), non-probabilistic convenience sampling technique was adopted. A standardized and validated (Student Evaluation of Educational Quality, SEEQ) questionnaire was sent to the students of all five years of MBBS on Moodle LMS. The responses of students who had attended at least one or more (live or recorded) online lecture were included in the study. The students who had not attended any online lecture were excluded from the study. The SEEQ questionnaire is internationally validated questionnaire. The reliability of questionnaire was considered good (average $=0.9$ ) with 1015 students. ${ }^{1,12}$ The questionnaire comprised of 
twenty-six standardized questions spread across different dimensions of effective teaching. The first nineteen questions were measured using a five-point Likert scale (range: 1, Not applicable; 2 , strongly disagree; 3 , disagree 4, agree; 5, strongly agree). The next six questions were measured using a five-point scale (range: 1 , very poor; 2, poor; 3, moderate; 4, good; 5, very good). Questions were related to different dimensions, including learning, enthusiasm, organization, interaction, examination and assignment. The last part involved the participant's overall view of the webinar and recorded sessions. Additional question ('Additional comments') was an openended question designed specifically to obtain any suggestions that might have been missed in the questionnaire regarding the current scenario. The results were analyzed as percentages and independent t-test was applied to find out the difference in satisfaction of students between $1^{\text {st }}$ year and $2^{\text {nd }}$ year with $3^{\text {rd }}, 4^{\text {th }}$ and $5^{\text {th }}$ year students using Microsoft Excel 2010.

\section{RESULTS}

A total of 365 students responded to the questionnaire with $57 \% \quad(n=210)$ and $43 \%$ $(n=155)$ of the respondents being females and males respectively as that is the ratio of females to males in collectively in all the years.

\section{Synchronous Teaching (Webinar)}

The results showed that $65 \%(n=238)$ students felt that the facilitators were enthusiastic about teaching on webinar and $68 \%(n=248)$ of them feel that they were well-prepared for their lecture. During live lecture sessions, nearly half of the students (47\%, $n=170$ students), felt that the lectures did not facilitate taking notes. According to $74 \% \quad(n=269)$ students, the facilitators encouraged the students to participate in the discussion and ask questions. Overall, the senior students that are the $3^{\text {rd }}, 4^{\text {th }}$ and $5^{\text {th }}$ year students seemed more satisfied with Webinar lectures (52\%) compared with year 1 and 2 students (26\%) as shown in Figure-1. However the difference was not significant $(p=0.17)$ For the purpose of analysis, "strongly agree and agree" and "strongly disagree and disagree" options were combined under "agree" and "disagree" respectively in the figure.

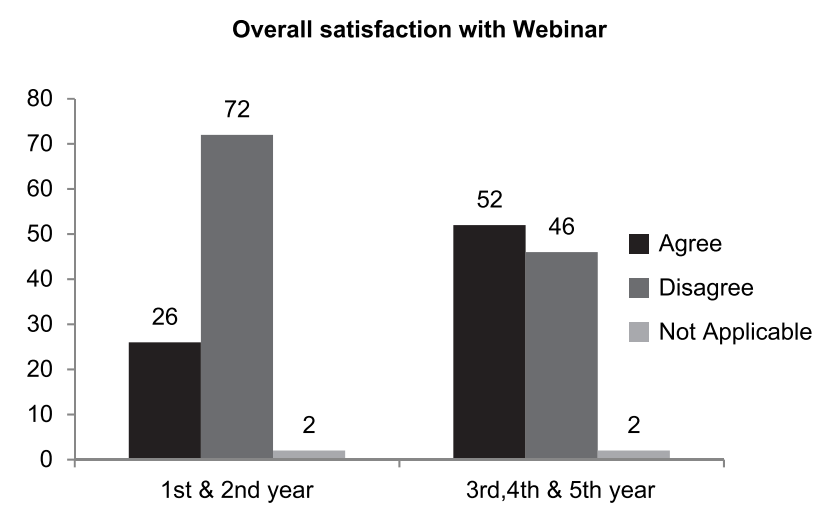

Figure-1. Satisfaction of students with webinar.

Asynchronous Teaching (Moodle and YouTube) Nearly half $(56 \%, n=206)$ of the students believed that the students were given an opportunity to interact with their facilitators even if the lectures were recorded by providing them with the facilitators' e-mail ID or contact number. 51\% $(n=185)$ students showed dissatisfaction over assignments and assessment protocols. However $67 \%(n=247)$ of the students showed satisfaction regarding the availability of resource materials on Moodle. Majority of the students $(82 \%, n=299)$ showed contentment with the privacy provided for their test or assignment results on Moodle. $80 \%(n=293)$ students agreed that in case they had missed a live lecture, its recording was readily available for them on YouTube. Overall, the students from senior classes $\left(3^{\text {rd }}, 4^{\text {th }}\right.$ and $5^{\text {th }}$ year) seemed more satisfied with Moodle as compared to $1^{\text {st }}$ and $2^{\text {nd }}$ year students as shown in Figure-2. However, there was no significant difference between their responses for satisfaction with Moodle $(p=0.23)$. For the purpose of analysis, "strongly agree and agree" and "strongly disagree and disagree" options were combined under "agree" and "disagree" respectively in the figure.

The students perceived the technical support provided to them as shown in Figure-3.

Additional comments, after detailed review, were grouped broadly into four categories i.e. Lectures, Assessments and Assignments. Most of the 
comments fell under the first two categories.

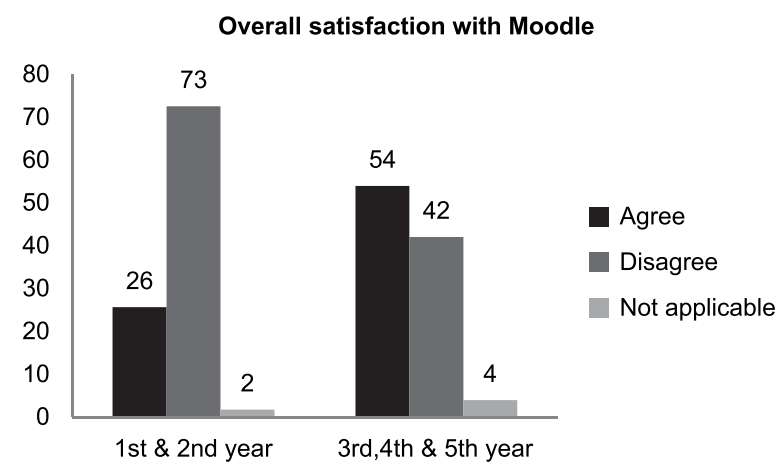

Figure-2. Satisfaction of students with Moodle.

Technical Support

Good Moderate Poor

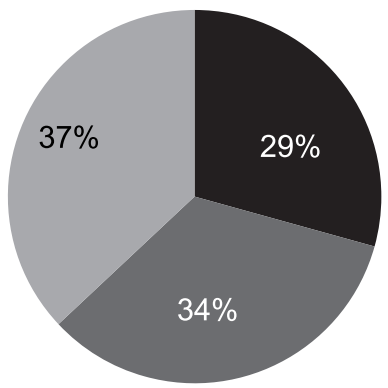

Figure-3. Students' perception of technical support received for the sessions.

\section{Lectures}

Comments pertaining to lectures were, in most part, positive where one respondent said "Although face to face lectures cannot be replaced by any other teaching method, but in this time of crisis, of all the colleges and universities I have heard so far who are facilitating students with online class, SMDC is going on top by starting online class, uploading them and taking tests side by side".

Another highlighted "teachers are putting a lot of efforts. It has been just an extra burden on them to teach us via this new medium and to i assume many of them had to learn this new tech system. We are very thankful to them for putting so much of hard work".

However students did remark upon lack of substitution for doctor-patient interaction. One student suggested "Please devise a list of learning objectives for rotations. We are unable to learn majority of things that are patient based due to current pandemic and that limits the things that can be discussed".

Also frequently mentioned were issues regarding audio/video errors, on both student's as well as facilitator's end, and problem faced acclimating oneself to E-learning. "I feel so fatigued after attending online lectures as they cause more strain on my eyes". A few students also applauded efforts made regarding asynchronous teaching modalities. "The recorded lectures on YouTube are awesome. Many times i have connection problem and can easily get them on YouTube".

\section{Assessments}

Regarding assessments students were generally happy about the effort put in by the faculty and institution by maintaining regular schedules. "I appreciate what my institution is doing for us even in this pandemic situation". "Assessments are going well, test content is from syllabus and after test they solve our queries".

Another prevalent view seemed to be insufficient time for preparation and app crashes due to heavy traffic flow that resulted in waste of precious time. "The time we get for assessments is not enough as we are not really good with typing on computers and have not a satisfactory typing speed. Also the system crashes mostly during assessments which stops the assessment and eventually affects our grades as we are unable to complete our examination on time."

\section{Assignments}

Majority comments regarding assignments highlighted students' dissatisfaction with the high frequency and short deadlines of submissions of assignments. One respondent said "Being an inhabitant of a remote village, I was facing internet issues and sadly I didn't receive any sort of leniency regarding extension of submission time of daily assignments".

A popular opinion was that assignments should be given only once a week, instead of 
current practice of daily assignments. A student suggested further saying "Moodle system should be an essential part of our medical college. These assignments should be a part of curriculum".

\section{DISCUSSION}

Undergraduate medical studies need dedication, devotion and hard work on part of both teachers and students. It requires the students to be self-directed learners with teachers acting as facilitators. The COVID-19 rapidly engulfed the world rapidly and country-wide lockdown was imposed suddenly leaving no time for medical colleges to train the students on E-learning or to mentally prepare them for the substituted teaching methodologies. Since the lockdown was imposed for an undecided period so it was the need of the hour to continue medical education via alternative methods in order to avoid educational loss of medical students. Online classes were initiated in the first month of lockdown and the satisfaction of students was surveyed after 2 months.

The overall dissatisfaction of students with E-learning media in $1^{\text {st }}$ and $2^{\text {nd }}$ year shows that the students were not mentally prepared for the sudden change in teaching methods. The $1^{\text {st }}$ year students had recently joined the medical college nearly two to three months before the lockdown and were becoming accustomed to the campus environment when everything came to a halt suddenly. It is assumed that this could be the reason for their mental unpreparedness. A previous study conducted during the said crisis also noted that the students felt mentally unprepared due to the sudden transition from traditional to E-learning. ${ }^{13}$ The students' responses stipulated that facilitators were encouraging participation from students in synchronous lectures. Student interactions were not possible during asynchronous lectures however the students were satisfied with the resource material available on Moodle to assist them in assignments. Kaur et al. ${ }^{14}$ noted that one of the shortcomings of E-learning compared with traditional face-toface lectures is the lack of interaction between teachers and student. Majority of the students applauded the asynchronous lectures as their accessibility was made possible on YouTube channels. The students prefer recorded lectures on YouTube because they can access them at their own convenience or in case they had missed a session. ${ }^{15}$

The students appreciated the hard work of the teachers but showed concern particularly about learning during clinical rotations as there are several limitations when teaching clinical subjects online. Several students were concerned about technical glitches faced during sessions especially during assessments and submission assignments. It was assumed that all the students had access to gadgets and uninterrupted connection of internet at home. Therefore, the students showed discontent over the technical support provided by the institute. Availability of internet and connectivity issues seems to be a major challenge that E-learning encounters in developing countries. ${ }^{16}$

Students suggested that E-learning particularly asynchronous online teaching should be made a regular part of teaching methodology even after COVID-19. It is believed that E-learning cannot completely substitute traditional face-to-face teaching however blended teaching approach should be used as it has shown to improve student learning. ${ }^{17}$

Overall, the findings of our study showed that students especially the $1^{\text {st }}$ and $2^{\text {nd }}$ year students were not mentally prepared for the sudden paradigm shift from traditional to online teaching and it is advisable to adopt a blended approach initially before converting the entire learning experience on online media. ${ }^{18}$ However the students realized that this gradual shift was not possible in the current scenario and were generally satisfied with synchronous and asynchronous sessions.

\section{LIMITATIONS}

Our study was conducted at one institute so cannot be generalized over the whole population.

\section{CONCLUSION}

Online classes were the only solution to the huge educational loss of Medical students during 
lockdown however they were not a replacement to traditional face-to-face teaching methodologies. E-learning will become an essential teaching tool in the coming years and both faculty and students should be trained to utilize it for their best interests.

\section{RECOMMENDATIONS}

It is recommended that the assignments and assessments should be designed in a way that a flexible timeline can be provided to students keeping in mind the connectivity and power outage issues. Secondly, Moodle and YouTube should be made part of the blended teaching approach even after the college restarts with face-to-face lectures. However, the college will have to ensure availability of internet connection for each student. The study should be conducted on teachers as well in order to find out their satisfaction with the E-learning protocols of the medical college.

Copyright@ 02 Nov, 2020.

\section{REFERENCES}

1. Knipfer C, Wagner F, Knipfer K, Millesi G, Acero J, Hueto JA, Nkenke E. Learners' acceptance of a webinar for continuing medical education. International journal of oral and maxillofacial surgery. 2019 Jun 1; 48(6):841-6.

2. Stein GH, Gainesville F, Shibata A, Kojima Bautista M, Tokuda Y. Web Seminar for Medical Students-Webinar: An initial experience with web-based real time interactive clinical seminars for Japanese medical students. $2010 ; 11(2): 87-90$.

3. Popovic N, Popovic T, Dragovic IR, Cmiljanic O. A Moodle-based blended learning solution for physiology education in Montenegro: A case study. Adv Physiol Educ. 2018; 42(1):111-7.

4. Adamiak JP, Sauls RD. Influencing mathematics students' academic success through online intervention: A case study. South African J High Educ. 2017; $31(3): 230-48$.

5. Wieling MB, Hofman WHA. The impact of online video lecture recordings and automated feedback on student performance. Comput Educ. 2010; 54(4):9928.

6. Martin-Smith J, McArdle A, C-J of P, 2015 U. Webinar: A useful tool in plastic surgery specialty trainee education. J Plast Reconstr Aesthetic Surg. 2015; 68(9):1323-4.
7. Mayorga E, Bekerman J, Journal AP-MEA, 2014 U. Webinar software: A tool for developing more effective lectures (online or in-person). Middle East Afr J Ophthalmol. 2014; 21(2):123.

8. Of J, Lieser P. The webinar integration tool: A framework for promoting active learning in blended environments. J Interact Media Educ. 2018; 2018(1):18.

9. Jaffar $A A$. YouTube: An emerging tool in anatomy education. Anat Sci Educ. 2012 May; 5(3):158-64.

10. Luo L, Cheng X, Wang S, Zhang J, Zhu W, Yang J, et al. Blended learning with Moodle in medical statistics: An assessment of knowledge, attitudes and practices relating to e-learning. BMC Med Educ. 2017 Sep 19; $17(1)$.

11. Marsh HW. SEEQ: A reliable, valid, and useful instrument for collecting students' evaluations of university teaching. British journal of educational psychology. 1982 Feb; 52(1):77-95.

12. Hoq $M Z$. E-Learning during the period of pandemic (COVID-19) in the Kingdom of Saudi Arabia: An empirical study. American Journal of Educational Research. 2020 Jul 5; 8(7):457-64.

13. Abbasi S, Ayoob T, Malik A, Memon SI. Perceptions of students regarding e-learning during covid-19 at a private medical college. Pakistan J Med Sci. 2020; 36(COVID19-S4):S57-61.

14. Waheed, M., Kaur, K. and Qazi, A. "Students' perspective on knowledge quality in eLearning context: A qualitative assessment", 2016; 269 (1): 120-145.

15. Rafi AM, Varghese PR, Kuttichira P. The pedagogical shift during COVID 19 pandemic: Online Medical Education, Barriers and Perceptions in Central Kerala. J Med Educ Curric Dev. 2020; 7:238212052095179.

16. Subedi S, Nayaju S, Subedi S, Shah SK, Shah JM. Impact of E-learning during COVID-19 pandemic among nursing students and teachers of Nepal. Intl J of Sci Healthcare Res. 2020; 5(3):68-76.

17. Education MJ-I journal of medical, 2012 U. Comparison of lecture and blended teaching methods on learning and satisfaction of medical students in biochemistry course. J Adv Med Educ Prof Med. 2012; 2(4):146-50.

18. Hoic-Bozic N, Mornar V, On IB-I transactions, $2008 \mathrm{U}$. A blended learning approach to course design and implementation. IEE Trans Educ. 2008; 52(1):19-30. 


\begin{tabular}{|c|l|l|}
\hline \multicolumn{2}{|c}{ AUTHORSHIP AND CONTRIBUTION DECLARATION } \\
\hline Sr. \# & Author(s) Full Name & \multicolumn{1}{|c|}{ Contribution to the paper } \\
\hline 1 & Sundus Iftikhar & $\begin{array}{l}\text { Conceived the idea, analysis and } \\
\text { interpretation of the results and } \\
\text { was a major contributor in writing } \\
\text { the manuscript. } \\
\text { Analyzed the results, Manuscript } \\
\text { writing and critical revision. } \\
\text { Acquisition of data, Manuscript } \\
\text { writing and critical revision. } \\
\text { Participated in the design of } \\
\text { the study, performed statistical } \\
\text { analysis and contributed in } \\
\text { manuscript writing. }\end{array}$ \\
\hline 4 & Ahmad Shafique & Iqra Aziz
\end{tabular}

